Check for updates

The BMJ

Cite this as: BMJ2020;370:m3472 http://dx.doi.org/10.1136/bmj.m3472 Published: 04 September 2020

\section{Covid-19: Hydrocortisone can be used as alternative to dexamethasone, review finds}

\author{
Elisabeth Mahase
}

Hydrocortisone can be used as an alternative to dexamethasone to treat patients severely ill with covid-19, researchers have said after reviewing the latest data.

The WHO Rapid Evidence Appraisal for Covid-19 Therapies (REACT) Working Group conducted a meta-analysis of seven trials that evaluated corticosteroids (mainly hydrocortisone or dexamethasone) in 1703 critically ill patients in 12 countries from 26 February to 9 June 2020, with final follow-up on $6 \mathrm{July}$. $^{1}$

They reported in JAMA that, when compared with usual care or placebo, dexamethasone and hydrocortisone reduced the risk of death by about a third (fixed effect summary odd ratio for association with mortality 0.64 ( $95 \%$ confidence interval 0.50 to 0.82 ) with dexamethasone and 0.69 ( 0.43 to 1.12; $\mathrm{P}=0.13$ ) with hydrocortisone), while methylprednisolone showed a smaller effect (o.91 (0.29 to 2.87)).

The findings support those of Oxford University's RECOVERY trial, which reported in June that dexamethasone reduced deaths in ventilated patients by a third and deaths in other admitted patients receiving oxygen by a fifth. ${ }^{2}$

Having another treatment option could help alleviate any future supply issues and should allow clinicians to use whichever of the two drugs they are most comfortable with, the researchers said. WHO has now published clinicians' guidance on corticosteroids for covid-19, recommending their use in severely and critically ill patients only. ${ }^{3}$

The seven trials included in the meta-analysis were DEXA-COVID 19, CODEX, RECOVERY, CAPE COVID, COVID STEROID, REMAP-CAP, and Steroids-SARI.

In terms of serious adverse events, six of the trials reported 64 events among 354 patients randomly allocated to corticosteroids and 80 events among 342 patients randomly allocated to usual care or placebo. The authors assessed the risk of bias as "low" in six of the seven mortality results, as "some concerns" were raised about the randomisation method in the other trial (Steroids-SARI).

\section{Class effect}

Speaking at a Science Media Centre briefing on the findings, Jonathan Sterne, professor of medical statistics and epidemiology at the University of Bristol and deputy director of the NIHR Bristol Biomedical Research Centre, said, "The overall results support and are consistent with the findings from RECOVERY that corticosteroids reduce mortality in the sickest patients with covid-19.

"What we add is that these are a diverse group of patients from a variety of countries, and we have a consistent message from all these trials. The effect of hydrocortisone is also consistent with the effect of dexamethasone."

Anthony Gordon, anaesthesia and critical chair at Imperial College London and consultant in intensive care medicine at St Mary's Hospital, said, "It is a class effect of the steroid-there is more than one choice. This means there should be better world supply, there should not be any shortages, and if there are supply issues people can use one or the other. Doctors should use the drug they're most familiar with."

The researchers noted some limitations of their study, including that the investigators of trials that did not take part in the meta-analysis may have declined the invitation because of their results. Additionally, the only trial that assessed methylprednisolone (Steroids-SARI) was very small and had raised concerns.

The team added that definitions and reporting of serious adverse events were not consistent across the trials, follow-ups were often not completed post-discharge, and the trials were mainly conducted in high income settings.

1 WHO Rapid Evidence Appraisal for COVID-19 Therapies (REACT) Working Group. Association between administration of systemic corticosteroids and mortality among critically ill patients with covid-19: a meta-analysis. JAMA2020 (published online 2 Sep). doi: 10.1001/jama.2020.17023. https://jamanetwork.com/journals/jama/fullarticle/2770279?alert=article.

2 Mahase E. Covid-19: Low dose steroid cuts death in ventilated patients by one third, trial finds. BMJ2020;369:m2422. doi: 10.1136/bmj.m2422 pmid: 32546467

3 World Health Organization. Corticosteroids for covid-19: living guidance. 2 Sep 2020. https://www.who.int/publications/i/item/WHO-2019-nCoV-Corticosteroids2020.1.

This article is made freely available for use in accordance with BMJ's website terms and conditions for the duration of the covid-19 pandemic or until otherwise determined by BMJ. You may use, download and print the article for any lawful, non-commercial purpose (including text and data mining) provided that all copyright notices and trade marks are retained. 